\title{
Study on the Core Problem and Compensation Pattern of Ecological Compensation Mechanism in Jialing River
}

\author{
Jiaxiu Sun ${ }^{1, \text { a }}$, Xiaoqing Zhou ${ }^{2, b}$ \\ 1 Business College, China West Normal University, Nanchong, PRC. \\ 2 Center of Education Information Technology, China West Normal University, Nanchong, PRC. \\ a sunsky12@126.com ,' zhousun123@163.com
}

\begin{abstract}
Keywords: Jialing river basin;basin ecological compensation mechanism;compensation pattern classification;sustainable development

Abstract. The development of the basin is not only the comprehensive development and utilization of river basin and governance issues, should also be under the guidance of sustainable development thought, the basin, including environment, resource, society, economy, various factors as a whole, in order to better promote the development of river basin ecological environment protection and social economic. And how to effectively measure the regional complex system of "natural, social, and economic" is the river basin sustainable development research hotspot and difficulty. This article targeted analysis of the core issue of Jialing river basin ecological compensation and the key link through analyzing to the Jialing river basin ecological environment and the situation, and then proposes the Jialing river basin ecological compensation system arrangement and mode choice, to better protect and repair the basin ecological environment, narrow the economic differences between upstream and downstream river basin.
\end{abstract}

\section{Introduction}

River basin is a comprehensive system which is made of national factors such as water, land, and human factors. And it is not only the main place for all kinds of economic activities but also a stabilizer for ecosystem to circulate materials and power and to keep balance. Because there are not powerful binding and adjustable system so the local government pursues partial and local interests. All the activities deteriorate ecosystem and hamper river basin development.

\section{Brief introduction on JiaLin River}

\section{The natural conditions of JiaLin River}

Jialing River is a first tributary of ChangJiang River and the river basin covers Shanxi, Gansu, Sichuan and Chongqing. The mainstream rises in Shanxi Province, passes Gansu, Shanxi, Sichuan. The river basin area is 159800 square kilometer. The part of SiChuan is 101920 kilometer which amounts to 63.8 percent of all the area. The mainstream is 1119 meters. The river basin is the biggest among all the steams of ChangJiang River. The upper reaches of Jialing River has few population and cultivated land.

\section{The eco-environment of Jialing River}

Jialing river basin possesses important locational advantage which is the river artery join Shanxi, Gansu and Sichuan and the important economic area. And it has three features as follows:

Firstly, it has obvious difference and binary (Table 1). There are obvious difference among upper reaches, middle reaches and lower reaches. It is more developed from upper reaches to lower reaches. Mianyang and Suining are more developed because of better natural condition and better location. Guangan and Nanchong close to Chongqing are developed. But Guangyuan, Dazhou and Bazhong are less developed. On the whole, the more closed to Chengdu or Chongqing, the more developed it is

(Fig.1) . So the obvious difference do doubt will hamper the integrated development of Jialing river basin and it is the core to develop middle and upper reaches and northern-east of Jialing river basin. 
Secondly, most of the Jialing river basin are special area and less developed. They are former revolutionary areas including Shanxi and Sichuan, impoverished mountainous areas, ecology sensitive areas and disaster prone area.

Thirdly, Jialing river basin is resource-abundant areas including green resource, red resource and gas resource. The compressive plan consists of five ecosystems, such as: forest ecosystem, prairie ecosystem, agro ecosystem, wetland ecosystem and town/village ecosystem.

Table 1 Data of Development Level in Jialing River Basin （2016）

\begin{tabular}{|c|c|c|c|c|c|c|c|}
\hline \multirow{2}{*}{$\begin{array}{l}\text { The main areas of the Ira ling River } \\
\text { Thres countias of Sha nui }\end{array}$} & \multirow{2}{*}{$\frac{\text { Population }}{61.62}$} & \multicolumn{6}{|c|}{ GDPT The Ist industry The 2nd industry The Birdindustry GDP Per capita Urbanizationrat te } \\
\hline & & 216.2 & 28.4 & 1303 & 57.5 & 35097.4 & 35.4 \\
\hline Hui county in Gansu & 21.99 & 33.8 & 9.7 & 14.2 & 9.9 & 15370.6 & 32.2 \\
\hline Cuangun & 253.00 & 468.8 & 918 & 225.6 & 151.4 & 18529.6 & 34.2 \\
\hline Eazhong & 33079 & 390.4 & 93.1 & 167.4 & 129.9 & 11802.0 & 30.2 \\
\hline Nanchong & 630.03 & 11804 & 2705 & 609.7 & 500.2 & 18735.6 & 39.3 \\
\hline Cuengen & 321.64 & 752.2 & 140.0 & 392.7 & 219.5 & 23380.1 & 35.6 \\
\hline Dazhou & 549.27 & 11367 & 249.0 & 6061 & 281.6 & 20694.7 & 36.1 \\
\hline Suining & 326.77 & 682.4 & 150.4 & 363.4 & 168.6 & 208832 & 39.6 \\
\hline Mianyang & 464.02 & 1948.1 & 219.2 & 707.2 & 421.7 & 29052.6 & 43.6 \\
\hline 4 districts and 1 county of Chongqing & Ig 472.10 & 17362 & 110.4 & 945.3 & 680.5 & 367761 & 67.7 \\
\hline
\end{tabular}

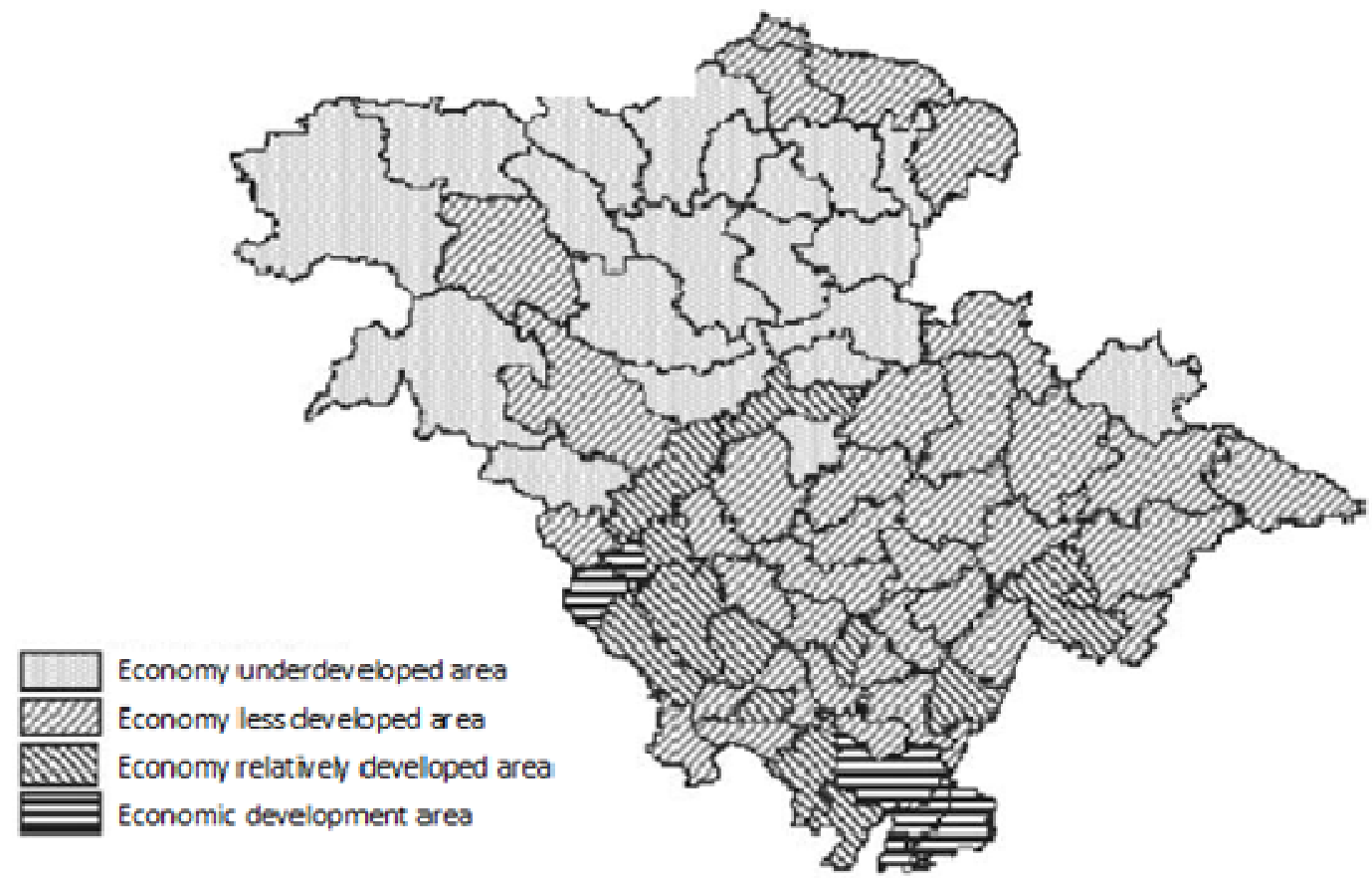

Fig.1 Divisions of Basin Economy of Jialing River Basin

\section{The ecosystem problem}

Although the abundant resource has made a great contribution to the areas, the ecosystem problem is getting more and more worse and hampered the development.

(1) Water and soil erosion is Serious and flood is susceptible. There are 2278 water conservancy projects, including 3 large reservoirs and 17 medium sized reservoirs amounts to 47.71 billion cubic meters which can irrigate 165.78 million mu. But due to natural reasons and excess reclamation, there are two areas which are serious water and soil erosion. One is located in ShangXi and GanSu. The other is located in the middle part of SiChuan. And the serious water and soil erosion cause to mud and sand. The erosion is 79445 square kilometers amounts to $49.65 \%$ of the total area. 
(2) Water pollution is Serous. Among 30 control units, there are 2 which are up to II water type, 12 which are up to III water type, 12 which are up to which are up to IV water type water type, 1 which are up to Vwater type, 3 which are up to bad Vwater type.

(3) It is difficult to solve River basin comprehensive development. Jialing River basin across four province (municipality), and 10 regions (cities). And there are several government sectors and operation entities engaged in the management of water resources. This management hampered optimal allocation of the water resources and protection of water resources.

\section{The Core Problem and key procedures of Ecological Compensation Mechanism in Jialing River}

\section{The core problem}

The core problem for Ecological Compensation in Jialing River includes the following three inspects: (1) The principle is the basic prerequisite. The principle consists of the following:

The principle of fairness. Ecological Compensation of river is to reduce negative external effect and redistribute wealth. And the core problem is the fairness; The principle of development. The Ecological Compensation should promote the marketization and industrialization; The principle of equality. All the parts should share the interest according to the contribution; The principle of operation. This is the basis to protect rive basin, including: to make the compensation standard, to consummate the legislation and to pursue for the positive policy.

(2)The objectives and scope of the compensation. Because ecological service has obvious externalities, so the compensation policy should indentify the suppliers and beneficiaries and the types of the supplies and beneficiaries.

(3) The regulation and legislation. The regulation and legislation can provide direct reference for the concerned policy including compensation principle, standard and some other.

\section{The key procedures}

The key procedures consist of the following:

(1) To indentify the type of the compensation

The type of the compensation is classified by the features of the rive basin. It can be classified 3 types from the main function of the river. The first one is water resource compensation. The second one is water resource conservation compensation. The third one is cross-administration region compensation. Of course, this classification is adjustable. There are 3 types according to the size of the river basin, including cross-province and cross-city compensation.

(2) To make the goal clear

The goal of water quality compensation is to keep the river basin healthy, harmonious and sustainable development by the compensation mechanism.

(3) To select the proper compensation method

(1) Fund compensation. The biggest beneficiary is the lower reaches. So the lower reaches government should compensate for the upper reaches. And the compensation fund comes from water price. So the lower reaches government may increase the fee of the water resource properly and take some part for the compensation fund. So does the upper reaches.

(2) Policy compensation. Policy compensation is the power and opportunity that higher government grants to the lower government. The receiver makes use of the priority and favorable treatment to boost the economic development and raise fund.

(3) Industry compensation. This is to solve the ecosystem compensation by industry transfer mechanism. And it should develop the industry of the upper reaches to narrow the gap between the upper reaches and the lower reaches.

(4) Market compensation. There is a prerequisite to emerge market mechanism, such as the sharp contradiction between supply and demand for the upper reaches and the lower reaches. Market compensation will be the trend with the development of the marketization. 


\section{The system and pattern}

\section{To establish concerned system}

The compensation system is the important system to protect ecosystem and coordinate difference. And this system should allocate the resources rationally considering the whole interest. So it needs many administrative sectors to cooperate. There are two systems for this, one is organization system and the other is consultation and arbitration system.

(1) The cross-province organization system is organized by the state. The cross-city organization system is organized by the province.

(2) The consultation and arbitration system. The higher government is responsible for the interest consultation between the upper reaches and the lower reaches. The consultation platform should be under the frame of the national security and consider the effect of the big river.

\section{To strengthen government accountability}

(1) To redistrict the responsibility of vertical government

The administrative right should be redistricted by the resource from the whole river basin. By doing this, it will make all the concerned interest parties take collective action and achieve mutual benefit.

(2) To strengthen government accountability of horizontal government

At present, fiscal system is decentralization, but administrative system is centralization in China. So the local governments have strong desire to pursue benefit and economy growth. And the competition between the local governments will exist forever. And it is very difficult to operate the cross-province river compensation system. So it is essential to strengthen government accountability of horizontal government for the cross-province river compensation system.

\section{The diversification of compensation pattern}

It will resolve some difficult to built up diversification money raising system for the present government dominant compensation. There are four types of compensation patterns:

(1) Direct compensation by government. The government compensates the person or corporation directly which is the most common pattern. For example, the American government subsidizes the farmers in order to improve the water quality and protect ecosystem by establishing nature reserve.

(2) Direct compensation by private. The person or cooperation in the lower reaches compensate for the certain objective of the upper reaches because of charity or risk management.

(3) Eco certification compensation. This pattern is a indirect way to pay ecologic service. It marks these products that do good to the ecosystem, such as organic food, green food. By the certification, the add-value of the product will be reflected and also the effect of the ecosystem protection. And the pattern will be changed from ecosystem construction cost compensation to ecosystem achievement compensation. In foreign countries, the certificated agriculture food and limber have been very popular and the price is two times more than the other products.

\section{References}

[1] Zheng haixia. Service compensation mechanism for watershed ecology in China and policy research [M]. Beijing: Chinese economic publishing house, 2010.

[2] Luo jun, Bai yongping. Jialing river basin economic space differentiation research [J]. Journal of resources and environment in Yangtze river basin, 2010,19(4) : $364-369$.

[3] Ding sibao. The basis of the regional ecological compensation theory and the practice question research [M]. Beijing: science press, 2010 .

[4] Wang junfeng, Hou chaobo. The government's leading river basin ecological compensation mechanism research: pairs of teeth river basin ecological compensation mechanism of thinking [J]. China population, resources and environment, 2011,21(7) : $101-106$. 
[7] Gao mei. The comparison and selection of compensation model in River basin ecological [J]. Journal of social science in jiangxi,2013 ( 11) : $45-47$. 